\title{
ELEMENTOS NÃO-ECONÔMICOS NA CONSTRUÇÃO DO MERCADO DO FUTEBOL: MITO DO HERÓI E FLEXIBILIZAÇÃO ŅA LEGISLAÇÃO
}

\author{
ELEMENTOS NO ECONÓMICOS EN LA CONSTRUCCIÓN DEL MERCADO \\ DE FÚTBOL: MITO DEL HÉROE Y FLEXIBILIZACIÓN EN LA LEGISLACIÓN
}

NON-ECONOMIC ELEMENTS IN THE CONSTRUCTION OF THE SOCCER MARKET: MYTE OF THE HERO AND FLEXIBILIZATION IN LEGISLATION

\author{
Maria Chaves JARDIM ${ }^{1}$ \\ Thierry VARELA ${ }^{2}$
}

RESUMO: O artigo trata da construção social do mercado do futebol no Brasil, buscando identificar elementos não-econômicos que ajudam a fundamentar este mercado. Com inspiração na sociologia econômica, argumenta que variáveis culturais (mito do jogador como herói) e variáveis sociais (flexibilização na legislação), ajudam a explicar a alta movimentação econômica desse mercado, sobretudo após os anos 2000. Teve como metodologia, pesquisa de campo na Ferroviária de Araraquara e pesquisa na internet.

PALAVRAS-CHAVE: Mercado do futebol. Sociologia econômica. Mito do herói. Transferências de atletas.

RESUMEN: El artículo trata de la construcción social del mercado del fútbol en Brasil, buscando identificar elementos no económicos que ayuden a basar este mercado. Con inspiración en la sociología económica, argumenta que las variables culturales (mito del jugador como un héroe) y las variables sociales (flexibilidad en la legislación), ayuda a explicar el alto dinamismo económico de este mercado, sobre todo después de la década de 2000. Tuvo como metodologia, el trabajo de campo em la Ferroviária de Araraquara y la investigacion em internet.

PALABRAS CLAVE: Mercado de fútbol. Sociología económica. Mito del héroe. Ttraslado de deportistas.

ABSTRACT: The article deals with the social construction of the soccer market in Brazil, seeking to identify non-economic elements that help to support this marketInspired by economic sociology, he argues that cultural variables (myth of the player as a hero) and social variables (flexibility in legislation), help to explain the high economic movement of this market, especially after the 2000s. It had as methodology the research of field in the Railway of Araraquara and research in the internet.

${ }^{1}$ Universidade Estadual Paulista (UNESP), Faculdade Ciências e Letras de Araraquara (FCLAr), Araraquara SP - Brasil. Professora Livre Docente do Departamento de Ciências Sociais. ORCID: https://orcid.org/00000001-5715-1430. E-mail: majardim@fclar.unesp.br

${ }^{2}$ Faculdade Ciências e Letras de Araraquara - (FCLAr), Araraquara - São Paulo -Brasil. Mestrando em Ciências Sociais (FCLAr). ORCID: https://orcid.org/0000-0002-8478-7837. E-mail: thierry.varela@unesp.br 
KEYWORDS: Football market. Economic sociology. Hero myth. Transfer of athletes.

\section{Introdução}

O futebol é o esporte mais praticado no país; há cerca de 30 milhões de pessoas interessadas nesse esporte e 500 times profissionais disputando campeonatos sob a legislação da Confederação Brasileira de Futebol (CBF) (ZANVIANI, 2017).

Como parte do processo, o mercado produzido pelo futebol mundial está, ano após ano, em constante movimentação, e tem cada vez mais relevância em termos de valores monetários. Esse mercado é constituído de diversas fontes de lucros, tais como o mercado publicitário, venda dos jogos para as redes de televisão, investimento na bolsa de valores e streaming e pay-per-view.

Isso sem esquecer o mercado imobiliário para a construção de estádios e infraestrutura para a realização de jogos e grandes eventos, o que ficou em evidencia, no Brasil, durante a construção e reforma de estádios para as Olimpíadas, de 2016 e a Copa do Mundo, de 2014. As obras foram realizadas pelo Estado brasileiro, a partir do Programa de Aceleração do Crescimento (PAC) (JARDIM, 2015).

Além disso, a venda de materiais esportivos, como uniformes e chuteiras, também é uma grande fonte de renda para clubes e patrocinadores. Por fim, não podemos esquecer os lucros resultantes das transferências de jogadores ao redor do mundo, especialmente na Europa, equivalente a 31 bilhões de reais ${ }^{3}$.

No Brasil, os números são menos expressivos do que os do mercado europeu; porém, não podemos dizer que há um baixo montante em movimentação de dinheiro no país, mesmo quando nos referimos apenas às transferências de jogadores. Um levantamento feito pela CBF e pela Federação Internacional de Futebol (FIFA), em 2016, indica uma movimentação de R\$ 311.421.250,00 recebido pelos clubes brasileiros, resultante de 614 transferências de atletas. E esses números aumentaram consideravelmente após os anos 2000, com a regulação das leis que flexibilizam o mercado do futebol. Em 2019, a FIFA contabilizou o total de 984 atletas que deixaram o Brasil, o que coloca o país como o primeiro do ranking de exportação de

3 Transferências internacionais em 2019 chegam a quase R\$31 bilhões, aponta relatório da FIFA. Globo Esporte, 2019. Disponível em: https://globoesporte.globo.com/futebol/futebol-internacional/noticia/gastos-comtransferencias-em-2019-chegam-a-quase-r-31-bilhoes-aponta-relatorio-da-fifa.ghtml. Acesso em: 08 abr. 2020. 
jogadores, gerando um mercado que, só em transferências, alcança cifras próximas a U\$ 371 milhões ${ }^{4}$.

Considerando o futebol como um objeto de estudo sociológico, o artigo tem como objetivo identificar elementos não-econômicos que ajudam a fundamentar este mercado. Nosso argumento é que o mito do jogador, como herói, permite uma romantização deste esporte, gerando uma alta oferta de jogadores; e que a flexibilização da legislação que trata das transferências de atletas, leva a dinamização desse mercado. As duas variáveis juntas, ajudam a explicar o funcionamento deste mercado. Inspira-se na sociologia econômica e teve como metodologia, pesquisa de campo na Ferroviária de Araraquara $^{5}$ e pesquisa na internet.

Além dessa Introdução e da Conclusão, o artigo está dividido em três sessões; na próxima, apresentamos o marco teórico que inspira essa pesquisa; em seguida, apresentamos o futebol como fenômeno sociológico; finalmente, na terceira seção, apresentamos os elementos não-econômicos identificados na pesquisa - mito do herói e flexibilização do marco jurídico no que se refere às transferências de jogadores.

\section{Referencial teórico-metodológico}

O fio condutor de nossa reflexão é a sociologia econômica, especialmente aquela que trata da construção social dos mercados. Esse campo da ciência, que tem sido reivindicado a partir dos anos 1970 (JARDIM; CANDIDO, 2019, p. 1) pelos chamados "sociólogos da economia", conseguiu unir e manejar as literaturas produzidas nas ciências econômicas e nas ciências sociais, principalmente a sociologia. Segundo Abramovay (2004, p. 10), a "economia é a ciência que explica como os indivíduos fazem escolhas, enquanto a sociologia se dedica a mostrar que eles não têm escolha nenhuma a fazer", já que suas escolhas estariam condicionadas por variáveis culturais, políticas, sociais, simbólicas. Portanto, a economia estaria enraizada em elementos não-econômicos.

Para esse argumento, os sociólogos da econômica se inspiram na tese clássica de Polanyi (1980), para quem o econômico está enraizado na vida social, de modo a demonstrar

${ }^{4}$ SIQUEIRA, I. Fifa: Brasil é o mais ativo no mercado de transferências internacionais em 2019. O Globo, 2020. Disponível em: https://oglobo.globo.com/esportes/fifa-brasil-o-mais-ativo-no-mercado-de-transferenciasinternacionais-em-2019-24205203. Acesso em 26 mar. 2020

${ }^{5}$ Ferroviária, como popularmente é conhecida, é uma associação esportiva da cidade de Araraquara, localizada no interior do Estado de São Paulo. Foi fundada em 12 de abril 1950 por um grupo de funcionários da ferrovia. Desde a estreia no campeonato paulista de 1956, a Ferroviária participa com frequência da elite do futebol paulista - entre descensos e acessos - destacando-se entre as equipes do interior do Estado. Em 2018 disputou a série D visando o acesso às divisões superiores do futebol nacional, como o feito dos anos 1980. 
que a separação entre o social e o econômico é um projeto utópico propagado pelos liberais e utilitaristas.

Para o autor, o liberalismo econômico interpretou os fenômenos causados pela Revolução Industrial de forma errônea. A filosofia liberal, para o autor, cometeu um erro crasso ao analisar e compreender o problema da mudança. $\mathrm{O}$ autor argumenta que o processo de produção e de distribuição econômicos estão ligados à interesses de natureza social. Em uma economia de mercado, como teorizada pelos intelectuais utilitaristas e liberais no século XIX, o sistema social como um todo, tem de se organizar para viver sob a égide dos conceitos fundamentais do mercado autorregulável, fenômeno esse que, segundo Polanyi (1980), nunca ocorreu na história da humanidade. Portanto, considerando a experiência histórica do fim do século XIX e começo do século XX, Polanyi afirma que o projeto de uma economia de mercado desenraizada é um projeto impossível de ser alcançado:

Nossa tese é que a ideia de um mercado autorregulável, implicava uma rematada utopia. Uma tal instituição não poderia existir em qualquer tempo sem aniquilar a substancia humana e natural da sociedade; ela teria destruído fisicamente o homem e transformado seu ambiente num deserto (POLANYI, 1980, p. 16).

Inspirando-se em Polanyi, Granovetter (2007) radicalizou o conceito de enraizamento, dando maior ênfase do que Polanyi ao enraizamento do econômico ao social. Para o autor, se nas sociedades pré-mercantis o comportamento econômico encontrava-se enraizado nas relações sociais, nas sociedades modernas a economia torna-se uma esfera diferenciada: as trocas econômicas não são mais definidas por obrigações sociais, mas por cálculo racional, voltado para maximizar o ganho. Ainda, o autor entende que os agentes econômicos também orientam sua conduta por objetivos que não são apenas puramente econômicos, mas sociais, como sociabilidade, reconhecimento, status e poder. Desse modo, Granovetter (2007) afirma a partir do conceito retirado da obra de Polanyi e de seu estudo empírico sobre o mercado de trabalho nos Estados Unidos- que as ações do agente econômico estão sempre enraizadas em redes sociais.

Nesse sentido, para o autor, não é possível criar um mercado autorregulável completamente desvinculado das demais relações humanas, pois a relação de mercado está completamente enraizada em redes de relações interpessoais (GRANOVETTER, 2007).

A partir de Polanyi, um conjunto de autores reivindicam a existência de elementos não-econômicos na construção de um mercado. Isso leva a um relativo consenso na sociologia econômica, a saber, de que "os fatos econômicos não ocorrem em um vazio, mas dentro de 
um marco social, composto por relações sociais variadas" (GRANOVETTER, 2007), que por sua vez envolvem cultura (ZELIZER, 2011), habitus e capitais (BOURDIEU, 2002), enraizamento social (POLANYI, 1980), reciprocidade (MAUSS, 2008), convenções cognitivas (DOUGLAS, 1986), política (FLIGSTEIN, 2001) e performatividade, (CALLON, 1988; STEINER,2016).

Considerando os pressupostos da sociologia econômica, de que todo mercado está enraizado no social, defendemos o argumento de que o mercado do futebol no Brasil, não se consolida em um vácuo social, variáveis culturais e sociais ajudaram a explicar o seu funcionamento. Como variável cultural, consideramos o mito do jogador como herói; como variável social, consideramos o aparato jurídico, especialmente no caso da transferência de atletas.

\section{Futebol no Brasil: gênese e constituição de um fenômeno sociológico}

O futebol foi inserido no Brasil no final do século XIX, fruto de tradição inglesa. Há dúvidas sobre quem trouxe o esporte ao país, se seria Charles Muller, que após estudar no Inglaterra teria trazido a prática esportiva para as terras brasileiras, ou se já era praticado anteriormente em escolas e grêmios operários de origem inglesa (PIMENTA, 1997).

No início, a tradição futebolística era praticada por apenas membros da elite brasileira, predominantemente branca e de origem estrangeira, principalmente inglesa, retomando às origens inglesas do desporto. $\mathrm{O}$ futebol foi, posteriormente, ligado às políticas ideológicas higienistas dos anos 1920 e 1930, como uma atividade positiva do corpo, saudável e higiênica, capaz de colocá-lo a serviço da pátria e do futuro (ANTUNES, 2004). Como dito por um dos pilares do movimento de modernização do Brasil, Olavo Bilac, o esporte também seria necessário e fundamental para a 'higiene social' destinada a 'limpar a raça' mestiça do Brasil (ANTUNES, 2004).

Segundo Pimenta (1997), a popularidade do futebol aumentava com o passar do tempo, e o esporte passou a deixar de ser praticado apenas pela elite e se popularizou pelas camadas baixas, como os imigrantes estrangeiros que vieram ao país e principalmente pela população de origem negra e operária. Sobre a popularização do futebol, Rodrigues Filho (1964) afirma que só podemos falar em sua popularização, a partir da inserção do negro na peleja, argumento compartilhado por Pimenta (1997).

De início, a reação brasileira à prática do futebol foi ambígua (PIMENTA, 1997), já que o desporto trazia um conjunto de regras - datadas e significadas de um processo de 
revolução industrial, na qual os valores burgueses e capitalistas eram representados no espírito competitivo -, completamente diferentes da realidade brasileira, em que a política clientelista, a prática do favor, a formação de hierarquias, não só sociais, mas éticas, morais e culturais, eram predominantes.

Por tais características, a busca da profissionalização do futebol foi cercada de dificuldades, tornando-se possível, graças à atuação do trabalho industrial, que levou o esporte para as camadas urbanas. Mais concretamente, a administração dos clubes por negociantes e industriais gerou a possibilidade de o atleta trabalhar na indústria e obter ganhos extras com os chamados "bichos"; e, acima de tudo, adquirir prestígio. (ANTUNES, 2004). Assim, o negro, juntamente com a classe operária, viu no futebol uma possibilidade de ascensão social, o que pode explicar, em alguma medida, a adesão desses grupos sociais ao esporte.

Paralelamente à prática do futebol, surgiram movimentos contrários à adesão do esporte como um caractere nacional, em que intelectuais como Lima Barreto e Graciliano Ramos lideraram a ideia de que o futebol, por ser um esporte de origem inglesa, não deveria ser praticado no país, pois seria um estrangeirismo, sem expressão dos valores nacionais; por outro lado, a prática esportiva nacional, deveria remeter-se aos esportes de origem nacional, como o murro, o cacete e a faca de ponta, como defendeu Graciliano Ramos, que não acreditava no futuro do futebol no Brasil (ANTUNES, 2004).

Conforme Antunes (2004) o futebol conseguiu superar as críticas nacionalistas e se tornou prática nacional, pelos quatro cantos do país, conquistando a população brasileira, desde a elite até as classes baixas; o mesmo autor informa, que o futebol chamou a atenção de jornalistas e políticos, que passaram a vincular esporte com a imprensa escrita e em transmissões de rádios, alavancando a popularização do futebol.

No Governo Vargas, com a criação do CND (Conselho Nacional de Desportos), ocorreu a primeira intervenção estatal relacionada ao futebol e existiram outras nas décadas seguintes: a tradição brasileira de civil law, permitiu que Vargas instaurasse não apenas leis relacionadas aos direitos civis, políticos e sociais, mas também colocou o Estado na função de regular os valores morais e éticos da sociedade - diferentemente das tradições de common law, em que a sociedade forma o Estado e nele implanta as tradições vinculadas à sociedade. Vargas via no futebol - então um esporte consagrado socialmente no Brasil -, um instrumento político de grande popularidade e passou a interferir diretamente nas administrações dos clubes através do CND. 
Portanto, durante o governo Vargas, o futebol foi utilizado como propaganda nacional (ANTUNES, 2004). Da mesma forma, houve investimento na construção de estádios, como o Pacaembu, em São Paulo, e o Maracanã, no Rio de Janeiro, investimentos esses que mexiam nas economias estaduais, dinamizando a geração de empregos. $\mathrm{O}$ auge dessas ações varguistas foi a Copa de 1950, realizada no Brasil, a qual colocou, finalmente, o Brasil no mapa do futebol (ANTUNES, 2004).

A interferência estatal no futebol também foi bastante presente nos governos militares, ganhando força no fim dos anos 1960 e se instaurando de vez nos anos de 1970, com o tricampeonato mundial da seleção brasileira. Nesse contexto, houve um importante agente presente nas ações militares, o então presidente da CBF, João Havelange, o responsável por levar o futebol para todo o país, com a criação do Campeonato Brasileiro de futebol, em 1971 (FRANCISCHINI, 2009).

A organização do Campeonato Brasileiro, de 1971, trouxe ineditismos na maneira administrativa que se conduzia o esporte no Brasil. Houve um processo de modernização de investimento em infraestrutura para sediar o campeonato, como a construção de estádios por todo o país, que garantiria a participação dos clubes no campeonato. Portanto, os clubes e os Estados investiram pesadamente na construção dos estádios, movimentando as economias locais e propagando o regime militar, com a ideia de modernização e geração de empregos.

Por fim, lembramos que o Brasil também sediou a Copa de 2014 e as Olimpíadas de 2016, quando igualmente fez investimentos econômicos consideráveis em infraestrutura na área do esporte, gerando emprego e movimentando a economia (JARDIM, 2015).

Considerando o breve excerto da história do futebol brasileiro apresentado, vimos que desde sua gênese o futebol foi um fenômeno sociológico complexo, permeado de diversas variáveis: econômica (movimentações financeiras de grande porte, geração de emprego e renda), política (o Estado como agente interno ou externo ao desporto), sociocultural (o futebol como parte do cotidiana de todas as classes sociais). Na próxima seção, destacaremos as variáveis culturais e sociais que identificamos em nossa pesquisa de campo. Como variável cultural, entendemos o mito do jogador como herói; como variável social, entendemos o marco jurídico do setor, especialmente aquele que facilita às transferências de atletas.

\section{Jogador como Herói: variável cultural}

Assumimos neste artigo que o mercado do futebol se sustenta em um discurso que está em oposição ao da racionalidade economia: o jogador como herói. Encontramos esse discurso 
durante nossa pesquisa de campo, realizada na Ferroviária de Araraquara, sendo que ele está presente em atletas profissionais e amadores. Nosso argumento é que este discurso ajuda no funcionamento do mercado, já que existiria, no Brasil, uma pré-disposição cultural que relaciona jogador e herói, ocasionando uma grande oferta de atletas.

No que se refere ao nosso trabalho de campo, informamos que o segundo autor desse artigo visitou a Ferroviária de Araraquara em dias de treino, observando e conversando informalmente com os jogadores. Além disso, conversou com ex-atletas da cidade. Nessas ocasiões, foi elaborado um Diário de Campo, no qual foi relatado as experiencias de dez jogadores neste clube e em outros pelos quais haviam passado. Esses relatos ajudam a elaborar a discussão que ora apresentamos nesse item.

Durante a pesquisa de campo, observamos ser comum entre os jogadores, histórias de superação; quanto mais superação um atleta mostra, mais valorizado ele é pela comunidade do desporto. É como se a superação, a forma positiva de encarar os desafios, fosse um marcador simbólico, uma ética que permite a aceitação pelo grupo.

Algumas das histórias de superação compartilhadas entre os jogadores, dizem respeito aos "atrasos de salários", "moradias precárias", "viagens de ônibus degradados", "materiais esportivos de segunda linha", "campos com condições adequadas para os treinos", "alimentação não satisfatória", "treinar com o estômago vazio" e acidentes durante os treinos e jogos.

Tomemos como exemplo o caso de Alessandro, 43 anos, que foi atleta profissional dos dezoito aos vinte e seis anos e que teve sua carreira interrompida por conta de uma lesão no pé direito. Apesar da tristeza em ter que abandonar o futebol "no auge da carreira", o exatleta fala com alegria do período em que viajou o Brasil com o futebol: "foi a melhor época da minha vida; não olhava as dificuldades e nem o salário, eu queria era jogar futebol; dar alegria para o torcedor". Sobre abandonar o futebol, fala com resignação: "são assim que são as coisas e devemos superá-las".

Falar do sofrimento com alegria e honra, ou seja, a romantização do sofrimento está presente não apenas em Alessandro, mas em todos jogadores com os quais conversamos. Assim, ouvimos casos sobre os "sacrifícios econômicos da família para conseguir a primeira chuteira"; sobre "dormir nas arquibancadas, nas vésperas de um teste, por não ter recurso para um hotel”; sobre "realizar o teste com fome, por falta de dinheiro”. Ouvimos muitos casos de exaltação das dificuldades e de superação diante das situações precárias; portanto, os jogadores se aproximam, mesmo sem perceber, do mito do jogador, como um herói. 
Segundo Rubio (2008), as qualidades heroicas têm seus valores definidos nos conflitos bélicos e na guerra, na Grécia Antiga:

[...]correspondem analogamente às virtudes necessárias para triunfar do caos. [...] Temos, então, que a vitória sobre si próprio é a grande propulsora do herói de todos os tempos. Diante dessa perspectiva o herói pode ser visto para além de um personagem, mas como uma forma que estrutura um padrão de atitude (RUBIO, 2008, p. 221).

Apesar de sublinharem que "o prazer é dar alegria ao torcedor", os atletas possuem como referência às histórias de atletas de sucesso e almejam receber salários acima da média nacional. A despeito de menos de $1 \%$ dos atletas receberem acima de $\mathrm{R} \$ 500$ mil mensais, segundo $\mathrm{CBF}^{6}{ }^{6}$ os jogadores produzem um discurso romantizado sobre a profissão. Esses atletas nos mostram, através de suas histórias de superação, que "os sacríficos valem a pena, pois serão futuramente, recompensados".

Não obstante, os discursos de dificuldade e superação, são encontrados, também, em atletas de sucesso, que passam a influenciar performaticamente os jogadores de clubes pequenos. Como exemplo ilustrativo, coletamos material escrito por Daniel Alves, para mostrar esse processo performático.

No texto $\mathbf{O}$ Segredo ${ }^{7}$, escrito pelo atleta no site The Players Tribune faz a seguinte afirmação: “Meu pai é um lutador. Eu tenho de ser um lutador, também”. Nesse material, o lateral direito do São Paulo e da Seleção Brasileira, remonta sua história desde os dez anos de idade, defendendo uma trajetória de dificuldade e superação. Conta a rotina de seu pai, trabalhador rural e de como ele e seus irmãos ajudavam na colheita - "Esta é a nossa forma de comer [...] sobreviver". Segundo Daniel, "meu pai foi um grande jogador quando jovem, mas não teve dinheiro para ir até a grande cidade” - o atleta é natural de Juazeiro, interior da Bahia - para ser notado pelos olheiros dos grandes clubes. Por conta disso, o pai deu todas as oportunidades para o filho ser atleta "mesmo que isso custasse a vida dele".

Daniel ainda relata que aos treze anos, foi treinar em uma academia de futebol para jovens atletas na cidade grande, morando distante de sua família. Em um alojamento pequeno com 100 jogadores, Daniel sentia-se em uma prisão. Tive meu uniforme de treino roubado e passei fome no alojamento, pois não tinha comida suficiente para todos os atletas. Uma

${ }^{6}$ ZARKO, R. Clubes pagaram R $\$ 1$ bi em salários em 2018; $7 \%$ dos atletas concentram $\mathrm{R} \$ 800$ milhões. Globo Esporte, 2019. Disponível em: https://globoesporte.globo.com/futebol/noticia/clubes-pagaram-r-1-bi-emsalarios-em-2018-7percent-dos-atletas-concentram-r-800-milhoes.ghtml. Acesso em: 7 abr. 2020.

${ }^{7}$ ALVES, D. O Segredo. The Players Tribune, 2017. Disponível em: https://www.theplayerstribune.com/enus/articles/dani-alves-juventus-o-segredo. Acesso em: 18 nov. 2019. 
passagem do texto mostra semelhança no discurso de Daniel Alves, atleta bem-sucedido, com o discurso que observamos na pesquisa de campo no Ferroviária:

Eu digo a mim mesmo: "Você não vai voltar para a fazenda até você deixar seu pai orgulhoso. Você pode ser o número 51 em habilidade. Mas você será o número 1 ou 2 em força de vontade. Você será um lutador. Você não vai voltar para casa, não importa o que aconteça.

Daniel não apenas se vê como herói, mas espelha-se em um outro que considera herói, seu pai. Adiante, o atleta mostra como se tornou um atleta que além de ser o mais vitorioso da história ${ }^{8}$ também trabalhou com aqueles que considera os melhores da sua geração, como o atacante argentino Lionel Messi e o treinador espanhol Pep Guardiola.

Daniel expressa de forma claro o que entendemos nesse texto como o mito do herói, corroborando com o que foi escrito por Rubio (2008), a saber, que a rotina de treinos e jogos transforma o atleta em um indivíduo isolado, que sofre com a ausência da família; e a ideia do herói o transforma em alguém incapaz de expor para o público suas fragilidades, angustias e incertezas. Então, o atleta torna-se ao mesmo tempo um showman, um indivíduo capaz de entreter e levar lazer e mover multidões rumo a estádios e ginásios (RUBIO, 2008) e também alguém solitário e frágil, carregando em si o mito do herói; como salienta Rubio (2008), o atleta acaba por desempenhar um papel paradoxal: ao mesmo tempo em que ganha muito dinheiro, vive intensa solidão.

A narrativa de Daniel é muito comum no ambiente do futebol; é possível encontrá-la no discurso de outros atletas, como Zé Roberto. A carreira de sucesso do atleta, marcada por passagens vitoriosas em grandes clubes do Brasil e da Europa, foi iniciada com muita dificuldade. Zé Roberto relata que "só me tornei atleta graças a minha mãe, que insistiu para que eu fizesse os testes de admissão nos clubes”; além disso, ele também relata a falta de materiais, como chuteiras, que o impossibilitava de treinar. No entanto, gosta de frisar que,

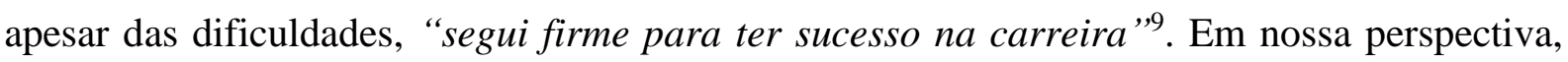
Zé Roberto, atual diretor esportivo na Sociedade Esportiva Palmeiras, tornou-se porta-voz do discurso do jogador como herói - ainda que não de forma consciente: atualmente é pastor de igreja evangélica e ministra palestras motivacionais, nas quais conta como sua carreira tornouse um case de sucesso.

${ }^{8}$ BATISTA, D. Daniel Alves chega ao $40^{\circ}$ título e amplia vantagem sobre Pelé. Estadão, 2019. Disponível em: https://esportes.estadao.com.br/noticias/futebol,daniel-alves-maior-campeao,70002910579. Acesso em 18 novembro de 2019.

${ }^{9}$ No meio futebolístico, Zé Roberto é conhecido por ter um por físico exemplar e por treinar mais que os atletas dos clubes pelo qual jogou. Encerrou a carreira como lateral esquerdo, uma posição que exige muito fisicamente, aos 42 anos de idade, algo muito raro. 
Essas narrativas focadas no sucesso individual, muito comum no ambiente do esporte, fazem parte de uma doxa contemporânea, que coloca trajetórias individuais como referência coletiva. Trata-se de uma estratégia bastante utilizada na literatura de autoajuda individual e corporativa (GAIAD, 2019), a qual defende que o sucesso e o fracasso de um agente se explicam isoladamente, desconsiderando referências sociais.

\section{Consequências sociais do mito do jogador como herói}

A romantização das dificuldades socioeconômicas no ambiente do futebol, possui, em termos macrossociológicos, consequências, tais como a ausência de políticas públicas para esse profissional, assim como acidentes de trabalho ligados ao futebol.

Tomemos como exemplo a tragédia ocorrida no Ninho do Urubu, centro de treinamento do Clube de Regatas do Flamengo (CRF), em 8 de fevereiro de 2019, quando dez meninos, de idades entre 14 e 16 anos, foram encontrados mortos no Ninho do Urubu, Flamengo. Segundo os veículos de comunicação, houve uma explosão em um aparelho de ar condicionado, causado o incêndio ${ }^{10}$.

O CRF é um dos clubes de futebol mais ricos do Brasil. O balanço financeiro do clube, em 2018, atingiu os R $\$ 543$ milhões, depois de um pico de $\mathrm{R} \$ 655$ milhões em $2017^{11}$. O prestígio do Flamengo atrai muitos atletas e faz com que o clube seja potência no futebol de base.

No entanto, após o acidente, revelaram-se descasos profundos com os atletas da base rubro-negra: os jovens atletas viviam em condições precárias nos alojamentos, feitos em containers. Segundo o site $\mathrm{G} 1^{12}$, o CT Ninho do Urubu não tinha alvará de funcionamento concedido pela Prefeitura do Rio de Janeiro, que multou o Flamengo e decidiu por interditar o espaço, que, mesmo assim, continuou funcionando.

As mortes dos Garotos do Flamengo ainda geram disputas judiciais entre o clube e os familiares das vítimas. Os valores das indenizações criaram uma celeuma: O Flamengo se dispôs a pagar entre R\$ 300 a R \$ 400 mil por família, negociado individualmente e não

${ }^{10}$ VEJA. O que se sabe sobre o incêndio do CT do Flamengo. Veja, 2019. Disponível em: https://veja.abril.com.br/brasil/o-que-se-sabe-sobre-o-incendio-no-ct-do-flamengo/. Acesso em: 10 jun. 2019.

${ }^{11}$ CAPELO, R.O Flamengo não investiu mais de R\$ 100 milhões em jogadores por acaso. Eis os números de 2018. Globo Esporte, 2019. Disponível em: https://globoesporte.globo.com/blogs/blog-do-rodrigocapelo/post/2019/04/02/o-flamengo-nao-investiu-mais-de-r-100-milhoes-em-jogadores-por-acaso-eis-osnumeros-de-2018.ghtml. Acesso em: 10 jun. 2019.

${ }^{12}$ G1. Ninho do Urubu não tinha alvará de funcionamento, diz prefeitura do Rio. G1, 2019. Disponível em: https://g1.globo.com/jornal-nacional/noticia/2019/02/08/ninho-do-urubu-nao-tinha-alvara-de-funcionamentodiz-prefeitura-do-rio.ghtml. Acesso em: 10 jun. 2019. 
coletivamente. O Ministério Público do Trabalho do Rio de Janeiro (MPT-RJ) sugeriu um valor de R\$ 2 milhões por família ${ }^{13}$.

Em 10 de outubro de 2019, o Flamengo ganhou uma ação na justiça e evitou a penhora da quantia de R 100 milhões de reais às famílias das vítimas. A sentença publicada pelo juiz do trabalho, Ricardo Georges Affonso Miguel, argumenta que o futebol de base não pode ser tratado como tema da justiça do trabalho, ao afirmar que essa categoria tem caráter recreativo:

Sendo assim, a atividade dos jovens de categoria de base de clubes de futebol está inserida no inciso IV, do art. $3^{\circ}$, da Lei Geral do Desporto, caracterizada por formação e com caráter recreacional ou recreativo, o que retira totalmente da natureza jurídica desta qualquer característica de aprendizagem. Posto isso, declaro a incompetência material da Justiça do Trabalho para julgar a matéria relacionada aos jovens em formação desportiva vitimados nas instalações da entidade de prática desportiva rée $e^{14}$.

O episódio reforça nosso argumento de que jogadores de futebol são vistos como heróis; e se os heróis são imortais, isso explicaria, em alguma medida, a ausência de atenção às condições de trabalho destes. Aliás, é o momento de afirmar que não existe uma previdência social e uma legislação trabalhista especifica para os jogadores de futebol no Brasil, conforme demonstrado em Varela (2019).

Finalmente, o item mostrou uma pré-disposição cultural do jogador de futebol para superar limites, tendo como referência seus atletas de sucesso. A busca romantizada pelo sucesso, aproxima-o do mito do herói; como consequência, afasta-o de políticas trabalhistas e previdenciárias, já que não existe uma política pública para essa categoria profissional. Em nossa perspectiva, a cultura do heroísmo ajudaria a explicar o funcionamento do mercado do futebol, já que a oferta de atletas é significativa no mercado brasileiro.

${ }^{13}$ NEDER, V. Flamengo quer indenizar famílias de vítimas de incêndio com o dobro da jurisprudência. ESTADÃO, 2019. Disponível em: https://esportes.estadao.com.br/noticias/futebol,flamengo-quer-indenizarfamilias-de-vitimas-de-incendio-com-o-dobro-do-valor-da-lei,70002734211. Acesso em: 10 jun. 2019.

${ }^{14}$ DANTAS, D. Flamengo ganha ação e evita penhora de R 100 milhões para famílias vítimas de incêndio no Ninho. O Globo, 2019. Disponível em: https://oglobo.globo.com/esportes/flamengo-ganha-acao-evita-penhorade-100-milhoes-para-familias-de-vitimas-de-incendio-no-ninho-24032390. Acesso em: 1 out. 2019. 


\section{Lei Bosman e Lei Pelé: flexibilização na lei de transferência de atletas}

Desde 2017, a transferência de atletas entre os clubes possui um importante marco na construção do mercado: a saída de Neymar do Barcelona para o Paris Saint-Germain pelo valor de 222 milhões de euros, referente a um contrato de cinco anos com o clube francês ${ }^{15}$.

Desde então, esse valor de transferência nunca foi alcançado, o que torna essa transação a mais cara da história do futebol. O efeito da transferência de Neymar desencadeou um processo inflacionário no mercado de transferência de atletas: das dez maiores compras e vendas da história, em valores absolutos, sete se deram depois da transferência de Neymar ${ }^{16}$. Ou seja, a movimentação de valores causada por uma única movimentação financeira entre dois clubes, produziu um efeito cascata inflacionário em todo o mercado de transferências europeu, que culminou, no ano de 2019, com o maior mercado da história do futebol, com números estimados em 31,8 bilhões de reais, sendo que, $75 \%$ desse valor refere-se aos clubes ingleses, italianos, espanhóis, alemães e franceses. ${ }^{17}$

Portanto, o mercado de transferência de atletas movimenta fortunas; para tanto, foi necessário modificações em seu marco regulatório ao longo dos anos, sendo a mais importante delas, a Lei Bosman de 1995. Trata-se de uma lei inspirada em Jean-Marie Bosman, ex-atleta profissional de futebol. A Lei Bosman modifica dois princípios tradicionais nas regras de transferência de atletas, que eram:

[...] pagava-se uma taxa de transferência quando um jogador tivesse seu contrato terminado e se quisesse mudar de clubes. Neste caso, tratava-se da tradicional venda do registro ou do passe do atleta de um clube para outro; (2) as ligas de futebol operam sob um sistema rígido, com o controle protecionista sobre o número de jogadores estrangeiros que poderiam jogar em um único time, tinha-se o sistema de cotas para atletas estrangeiros que poderiam atuar em uma única partida (SIMMONS apud RODRIGUES, 2007, p. 91).

Para Rodrigues (2007), Bosman argumentava que as regras de transferência de atletas violavam o artigo 48 do Tratado de Roma ${ }^{18}$, que garante o livre movimento de todos os trabalhadores europeus pertencentes à União Europeia. A regra de transferência passou, então,

${ }^{15}$ EL PAÍS. PSG anuncia contratação de Neymar e fecha acordo por cinco anos. EL PAÍS, 2017. Disponível em: https://brasil.elpais.com/brasil/2017/08/03/deportes/1501793043_883823.html. Acesso em: 30 set. 2019.

${ }^{16}$ Disponível em: https://www.transfermarkt.pt/statistik/transferrekorde. Acesso em: set. 2019.

${ }^{17}$ REIS, R. Maior da história, Mercado da Bola fecha em 31,8 bi; veja tudo que rolou. Blog do Rafael Reis, 2019. Disponível em: https://blogdorafaelreis.blogosfera.uol.com.br/2019/09/03/maior-da-historia-mercado-dabola-fecha-em-r-314-bi-veja-tudo-que-rolou/. Acesso em: 30 set. 2019.

${ }^{18}$ ARTICLE 48. 1 - Freedom of movement for workers shall be secured within the Community by the end of the transitional period at the latest. THE TREATY OF ROME, 25 March 1957. Disponível em: https://ec.europa.eu/romania/sites/romania/files/tratatul_de_la_roma.pdf. Acesso em: 30 set. 2019. 
por uma significativa mudança: se antes o atleta tinha seu registro ligado exclusivamente ao clube, e só poderia ser desligado ou ter seu contrato rompido a partir da vontade do contratante, com a Lei Bosman, o atleta passa a ter controle direto do seu registro. Assim, para transferir-se de um clube, basta ter a sua multa contratual paga pelo contratante.

Desse modo, a Lei permitiu significativa mudança no movimento de capitais e de direitos trabalhistas dos atletas do futebol europeu, no qual a liberdade de contrato e de escolhas individuais passaram a ser respeitadas. Segundo Rodrigues (2007), após a Lei Bosman, houve crescimento de desigualdades salariais, com o aumento dos salários de alguns atletas. $\mathrm{O}$ autor acrescenta que a desigualdade produzida pela diferença salarial dos atletas é um problema que precisa ser considerado, pois o futebol é um esporte coletivo; Desse modo, não é possível mensurar objetivamente como um atleta contribui individualmente para o desempenho de uma equipe em campo, ainda que o atleta seja considerado acima da média de seus companheiros de equipe.

No Brasil, o mesmo processo de liberalização dos contratos dos atletas aconteceu em 1998, com a Lei Pelé, do mesmo ano. O então chamado Passe - referência ao vínculo clubeatleta - foi substituído pelo contrato. Da mesma forma, passou a ser garantido pela lei Pelé, as normas gerais da legislação trabalhista e da seguridade social, como assegurado pela Consolidação das Leis Trabalhistas (CLT); também passou a ser garantido pela Lei Pelé, que o atleta faça a gestão da própria carreira, ao mesmo tempo em que garante aos clubes remunerações financeiras:

$\S 5^{\circ} \mathrm{O}$ vínculo desportivo do atleta com a entidade de prática desportiva contratante constitui-se com o registro do contrato especial de trabalho desportivo na entidade de administração do desporto, tendo natureza acessória ao respectivo vínculo empregatício, dissolvendo- -se, para todos os efeitos legais: I - com o término da vigência do contrato ou o seu distrato; II - com o pagamento da cláusula indenizatória desportiva ou da cláusula compensatória desportiva; III - com a rescisão decorrente do inadimplemento salarial, de responsabilidade da entidade de prática desportiva empregadora, nos termos desta Lei; IV - com a rescisão indireta, nas demais hipóteses previstas na legislação trabalhista; e V - com a dispensa imotivada do atleta (LEI PELÉ, p. 19, 2013).

A Lei Pelé modifica radicalmente a relação entre clube e atleta no Brasil e garante um sistema de capitalização do futebol, tornando o futebol uma prática que é, em primeira instância, econômica (ARAÚJO apud RUGGI, 2008). Tal característica da Lei Pelé permitiu o entusiasmo dos setores que defendem a liberdade de contrato no país. Nesse sentido, Luiz Fernando Bindi comparou, em 2001, a Lei Pelé com a Lei Aurea, pois liberta os jogadores das ordens espúrias dos dirigentes e do jogo cruel dos empresários (RUGGI, 2008). 
Segundo Ouriques (1999), a Lei Pelé, criada sob a gestão do então ministro Edson Arantes do Nascimento, o Pelé, representa a expansão de um surto mercadológico no futebol, que tinha se iniciado no final dos anos 1970. Ainda segundo Ouriques, a Lei Pelé traz em seu cerne, as reivindicações dos empresários do mercado do futebol.

Dito isso, o que defendemos nesse item, é que tanto a lei Bosman, de 1995, quanto a Lei Pelé, de 1998, flexibilizaram o mercado do futebol e marcaram uma profunda mudança na forma de gestão deste; no seu conjunto, as duas leis ajudaram na dinamização deste mercado após anos 2000, especialmente no que se refere às transferências de atletas.

\section{Considerações finais}

O artigo tratou do mercado do futebol, identificando elementos não-econômicos que ajudam a construir este mercado. Como elemento cultural, consideramos o jogador enquadrado no mito do herói; como elemento social, a flexibilização na legislação no que tange à transferência de atletas, o que levou a alta movimentação financeira neste mercado, a partir dos anos 2000.

Portanto, em oposição a um discurso da teoria econômica, que prega que todo mercado é assentado na racionalidade econômica, demonstramos que o mercado do futebol não se constrói em um vácuo social. Para além da racionalidade econômica, existiria elementos sociais e culturais na fundamentação deste mercado e selecionamos duas variáveis (dentre as inúmeras outras existentes) para esse artigo.

No que se refere à variável cultural, identificamos uma pré-disposição cultural nos jogadores amadores ou profissionais para a romantização das dificuldades da profissão, aproximando-o de um herói. Contudo, ao ser tratado apenas como atividade cultural, de lazer e de recreação, o mercado do futebol, constituído por trabalhadores (atletas) e empresa (clube), dão a falsa impressão de estarem desenraizados do econômico; ao contrário, o que argumentamos é que é justamente esse eufemismo - o futebol como recreação - que leva a uma certa naturalização das dificuldades enfrentadas pelos atletas, desde questões salariais à condições de trabalho. A busca individualizante pelo sucesso e a negação das dificuldades, aproxima o atleta do herói; como consequência, afasta-o de políticas trabalhistas e previdenciárias, já que não existe, ainda, no Brasil, uma política pública para essa categoria profissional. Em nossa perspectiva, essa cultura do heroísmo ajudaria no funcionamento deste mercado, já que ofereceria uma larga mão de obra (barata) para este mercado. 
No que se refere à variável social, expressa nesse artigo na flexibilização da legislação, apontamos que as leis Bosman de 1995 e a Lei Pelé, de 1998, marcam uma mudança importante neste mercado, sobretudo na forma de gerir o futebol. Essa mudança levaria a uma dinamização desse mercado, com uma alta movimentação financeira, especialmente após os anos 2000.

O estudo dessas duas leis mostra que o mercado do futebol deu maior liberdade individual ao atleta, que passa a decidir por sua própria carreira. Em diálogo com a sociologia econômica, o que buscamos demonstrar é que, mesmo quando a dita "mão invisível" do mercado parece funcionar muito bem, ela não o faz de forma isolada; foi a partir dos Estados e da regulação dessa legislação, que o livre mercado se fez. Isso vai em direção ao que nos ensinou Polanyi, a saber, que o mercado autorregulável em si, é uma utopia, já que, para existir, precisa se enraizar nas instituições sociais e culturais existentes; no caso estudado, o mercado autorregulável precisou do empenho dos Estados envolvidos.

Finalmente, em diálogo com os principais argumentos da sociologia econômica, defendemos que essas duas variáveis juntas - mito do jogador, como herói, que romantiza este esporte e a flexibilização da legislação que trata das transferências de atletas- ajuda certamente a melhor entender o poder econômico deste mercado, sobretudo a partir dos anos 2000 .

AGRADECIMENTOS: Agradecemos à Fapesp, agência que financiou essa pesquisa.

\section{REFERÊNCIAS}

ABRAMOVAY, R. Entre Deus e o diabo: mercados e interação humana nas ciências sociais. Tempo Social, revista de sociologia da USP, v. 16, n. 2, 2004.

ANTUNES, F. M. R. F. Com o brasileiro não há que possa: futebol e identidade nacional em Jose Lins do Rego, Mario Filho e Nelson Rodrigues. São Paulo: Editora Unesp, 2004. $304 p$.

BOURDIEU, P. A produção da crença: contribuição para uma economia dos bens simbólicos. São Paulo: Editora Zouk, 2002.

CALLON, M. The embeddedness of economic markets in economics. In: CALLON, M. (Ed). The law of the market. Oxford; Blackwell, 1998. p.1-57.

DOUGLAS, M. Como Pensam as Instituições. Colecção Sociedade e Organizações, sob a orientação de A Olivera Cruz Syracuse University Press, 1986. Editora Instituto Piaget, 2004. 
FLIGSTEIN, N. The architectureof markets: an economic sociology of 21 st century capitalist societies. Princeton: Princeton University Press, 2001.

FRANCISCHINI, S. A difícil nacionalização do futebol brasileiro: a era Havelange. In: TOLEDO, L. H.; COSTA, C. E. (Orgs.). Visão de Jogo: antropologia das práticas esportivas. Editora Terceiro Nome, 2009. p. 169-197.

GAIAD, M. A sociologia das emoções em Eva Illouz: o fenômeno da literatura de autoajuda. Araraquara: Programa de Pós-graduação em Ciências Sociais, 2019.

GRANOVETTER, M. Ação econômica e estrutura social: o problema da imersão. RAE eletrônica, v. 6, n. 1, jan./jun. 2007. Disponível em: https://rae.fgv.br/rae-eletronica/vol6num1-2007/acao-economica-estrutura-social-problema-imersao. Acesso em: 20 fev. 2020.

JARDIM. M. A construção social do mercado de trabalho no setor de construção civil nas obras do Programa de Aceleração do Crescimento (PAC): consensos e conflitos. Sociedade e Estado, Brasília, v. 30, n. 1, p. 165-187, 2015.

MAUSS, M. Ensaio sobre a dádiva. Edições 70, 2008.

MERTON, R. Theory and social structure. New York: Free Press, 1968.

OURIQUES, N. O gol contra do rei: a Lei Pelé e suas consequências. Motriviência, Florianópolis, v. 11, n. 12, 1999

PIMENTA, C. A. M. Torcidas organizadas de futebol violência e auto-afirmação.

Aspectos das novas relações sociais. Vogal editora 1997

POLANYI, K. A grande transformação: as origens da nossa época. Rio de Janeiro: Campus, 1980.Wrobel. Rio de Janeiro: Campus, 1980.

RODRIGUES FILHO, M. O negro no futebol brasileiro. Editora Civilização brasileira S.A., 1964.

RODRIGUES, F. X. F. O fim do passe e a modernização conservadora no futebol brasileiro (2001-2006). 2007. 346 f. Tese (Doutorado em Sociologia) - Universidade Federal do Rio Grande do Sul, Porto Alegre, 2007.

RUBIO, K. In: Legados de Megaeventos Esportivos. Editores: Lamartine DaCosta, Dirce Corrêa, Elaine Rizzuti, Bernardo Villano Ana Miragaya. Brasília: Ministério do Esporte, 2008

RUGGI, L. Transformações legais nas transferências internacionais de jogadores de futebol. In: CONGRESSO PORTUGUÊS DE SOCIOLOGIA, 6., 2008, Lisboa. Anais [...]. Lisboa, 2008.

STEINER, P. Altruísmo, dons e trocas simbólicas: abordagem sociológica da troca. Cultura Acadêmica, Série Temas em Sociologia, 2016.

VARELA. T. Jogadores de futebol como trabalhadores do esporte: aproximando aposentadoria e direitos previdenciários a partir da Sociologia Econômica. 2019. Monografia - Universidade Estadual Paulista, Araraquara, SP, 2019. 
ZANVIANI, L. N. Mediações na cultura de consumo: uma etnografia do circuito futebolístico na cidade de Araraquara. 2017. Monografia - Universidade Estadual Paulista, Araraquara, SP, 2017.

ZELIZER, V. A negociação da intimidade. Petrópolis: Ed. Vozes, 2011.

\section{Como referenciar este artigo}

JARDIM, Maria Chaves; VARELA, Thierry. Elementos não-econômicos na construção do mercado do futebol: mito do herói e flexibilização na legislação. Rev. Sem Aspas, Araraquara, v. 8, n. 2, p. 258-275, jul./dez., 2019. e-ISSN: 2358-4238. DOI: https://doi.org/10.29373/sas.v8i2.13556

Submetido em: 05/11/2019

Aprovado em: 19/12/2019

Publicado em: 30/12/2019 